Frontal Cortex Myo-Inositol Is Associated with Sleep and Depression in Adolescents : A Proton Magnetic Resonance Spectroscopy Study

\author{
Urrila, Anna S.
}

2017

Urrila , A S , Hakkarainen , A , Castaneda , A , Paunio , T , Marttunen , M \& Lundbom , N 2017 , ' Frontal Cortex Myo-Inositol Is Associated with Sleep and Depression in Adolescents : A Proton Magnetic Resonance Spectroscopy Study ', Neuropsychobiology , vol. 75 , no. 1 , pp. 21-31 . https://doi.org/10.1159/000478861

http://hdl.handle.net/10138/310859

https://doi.org/10.1159/000478861

acceptedVersion

Downloaded from Helda, University of Helsinki institutional repository.

This is an electronic reprint of the original article.

This reprint may differ from the original in pagination and typographic detail.

Please cite the original version. 


\section{Frontal cortex myo-inositol is associated with sleep and depression in adolescents: a proton magnetic resonance spectroscopy study}

Anna S. Urrila ${ }^{1,2^{*}}$, Antti Hakkarainen ${ }^{3}$, Anu Castaneda $^{4}$, Tiina Paunio ${ }^{5,6}$, Mauri Marttunen ${ }^{1,2}$, Nina Lundbom $^{3}$

${ }^{1}$ National Institute for Health and Welfare, Department of Health, Unit of Mental Health, Helsinki, Finland

${ }^{2}$ University of Helsinki and Helsinki University Hospital, Department of Psychiatry, Unit of Adolescent Psychiatry, Helsinki, Finland

${ }^{3}$ HUS Helsinki Medical Imaging Center, Radiology, University of Helsinki and Helsinki University Hospital, Helsinki, Finland

${ }^{4}$ National Institute for Health and Welfare, Department of Welfare, Equality and Inclusion Unit, Helsinki, Finland

${ }^{5}$ National Institute for Health and Welfare, Department of Genetics and Biomarkers, Helsinki, Finland

${ }^{6}$ University of Helsinki and Helsinki University Hospital, Department of Psychiatry, Helsinki, Finland

Short title: Frontal myo-inositol, depression and sleep in adolescents

Key words: adolescent, depression, frontal cortex, magnetic resonance spectroscopy, magnetic resonance imaging, myo-inositol, polysomnography, sleep, sleepiness, youth

*corresponding author

\section{Address:}

National Institute for Health and Welfare

Department of Health, Mental Health Unit

P.O.Box 30, 00271 Helsinki

Finland

Tel.: +358-40-351 8547

Fax: +358-9-761307

e-mail: anna.urrila@helsinki.fi 


\section{Abstract}

Aim: This study used proton magnetic resonance spectroscopy $\left({ }^{1} \mathrm{H}\right.$ MRS) to evaluate neurochemistry of the frontal cortex in adolescents with symptoms of sleep and depression.

Methods: 19 non-medicated adolescent boys (mean age $16.0 y ; n=9$ clinical cases with depression/sleep symptoms and $n=10$ healthy controls) underwent ${ }^{1} \mathrm{H}$ MRS at $3 T$. MR spectra were acquired from the anterior cingulate cortex (ACC), the dorsolateral prefrontal cortex, and frontal white matter. Concentrations of $\mathrm{N}$-acetyl aspartate, total creatine, choline-containing compounds, total glutamine plus glutamate, and myo-inositol $(\mathrm{ml})$ were compared between the two subgroups and correlated with sleep and clinical measures in the total sample. Sleep was assessed with self-report questionnaires and ambulatory polysomnography recordings.

Results: Concentrations of $\mathrm{ml}$ were lower in both frontal cortical regions among the depressed adolescents as compared to healthy controls. No statistically significant differences in other metabolite concentrations were observed between the subgroups. Frontal cortex ml concentrations correlated negatively with depression severity, subjective daytime sleepiness, insomnia symptoms, and the level of anxiety, and positively with total sleep time and overall psychosocial functioning. The correlations between $\mathrm{ml}$ in the ACC and total sleep time as well as daytime sleepiness remained statistically significant when depression severity was controlled in the analyses.

Conclusion: Lower frontal cortex $\mathrm{ml}$ may indicate a disturbed second messenger system. Frontal cortical $\mathrm{ml}$ may thus be linked to the pathophysiology of depression and concomitant sleep symptoms among maturing adolescents. Short sleep and daytime sleepiness may be associated with frontal cortex $\mathrm{ml}$ independently from depression. 


\section{Introduction}

Depression is tightly associated with disturbed sleep: so tightly that sleep disturbance is one of the diagnostic criteria of major depressive disorder [1]. The presence of symptoms of disturbed sleep has been linked with more severe forms of depression [2-4] and poorer depression treatment response [5]. The underlying neurobiological links between disturbed sleep and mood remain, however, obscure.

Adolescence is marked by increased incidence of depression and insomnia and dramatic changes in sleep patterns [6]. The trajectory of the maturational changes in sleep structure during adolescence matches temporally and topographically adolescent brain cortical maturation. Both the decrease in deep slow wave sleep and cortical grey matter reduction start from the occipital posterior regions and occur latest in the higher-order association areas of the frontal cortex [7-9]. Frontal cortex developmental processes continue until adulthood [10], making the frontal cortex vulnerable to aberrations in development still during late adolescence [11].

The prefrontal cortex (PFC), which is importantly involved in self-referential processing and regulation of mood states via its interactions with striatal and limbic structures, has been repeatedly implicated as a key brain region involved in the pathophysiology of depression across diverse age groups $[12,13]$. In depressed adolescents, both structural and functional changes in the PFC have been reported: a trend towards decreased regional volumes, abnormal cortical thinning, and reduced activation in cognitive control and decision making tasks [13]. The structure and function of the PFC have likewise been observed to correlate with sleep habits [14-16], sleep loss $[17,18]$, and sleep pathologies [19-21]. 
Proton magnetic resonance spectroscopy $\left({ }^{1} \mathrm{H}\right.$ MRS) allows to detect and measure in vivo several neurometabolites and thus to examine distinct neurochemical processes involved in the pathophysiology of depression. In depressed adolescents, ${ }^{1} \mathrm{H}$ MRS has revealed numerous but inconsistent findings in the frontal cortex. Both higher and lower levels of choline-containing compounds (Cho) have been reported in the medial frontal cortex and the left dorsolateral PFC (DLPFC) [22-24], higher myo-inositol (ml) levels have been observed in the DLPFC [24], and lower glutamate plus glutamine (GIx) and N-acetyl-aspartate (NAA) concentrations in the anterior cingulate cortex (ACC) have been found $[13,25,26]$. The first and thus far the only attempt to study the link between sleep, mood, and frontal ${ }^{1} \mathrm{H}$ MRS neurochemistry in young people with affective disorders found that a later sleep midpoint is associated with altered glutamatergic processes in the ACC, independent of depression severity [27]. In that study, diurnal rhythm and motor activity was measured with actigraphy from a rather heterogeneous group of 15-33 yearold adolescents and young adults with an emerging unipolar or bipolar disorder [27].

MRS findings suggest that cellular health and neurotransmission might be impaired in the frontal cortical areas in adolescents with depression. Further, it seems possible that sleep would also affect the same neurometabolic processes. However, the findings still remain inconsistent for several reasons. Most notably, the number of subjects studied is typically small in ${ }^{1} \mathrm{H}$ MRS studies, and the samples have been heterogeneous in terms of age, pubertal status, gender, psychotropic medication use, and the presence of other psychiatric comorbidities. Further, methodological approaches and brain areas studied have been variable. 
We hypothesized that frontal cortex ${ }^{1} \mathrm{H}$ MRS neurochemistry would be altered in depressed adolescents as compared to healthy controls. Further, we hypothesized that sleep symptoms would be associated with metabolite levels in a similar way than depressive symptoms. We studied this in a carefully evaluated and selected homogeneous sample of non-medicated adolescent boys and performed ${ }^{1} \mathrm{H}$ MRS in two frontal cortical regions (ACC, DLPFC), and additionally in frontal white matter (FWM; control region with no hypothesis of altered metabolism) with a 3 Tesla MR imager.

\section{Materials and methods}

\section{Participants}

A total of 20 non-medicated adolescent boys participated in the study. Ten of them were patients suffering from depressive and/or sleep symptoms recruited from the Helsinki University Central Hospital Department of Adolescent Psychiatry outpatient units, and ten were healthy controls recruited via advertisements for the hospital staff. Imaging data was not available for one adolescent in the patient group due to drop-out, leaving a total of 19 participants in the analyses presented. Written informed consent for study participation was received both from the participants and their parents or legal guardians and the study protocol was approved by the ethics committee of the Helsinki University Central Hospital.

Exclusion criteria for all participants included mental retardation, insufficient knowledge of Finnish language, current use of medication, age over 17.5 or under 14.5 years, chronic somatic illness, substance abuse/dependence, principal DSM-IV diagnosis other than depressive/sleep disorder, and any contraindications for brain MRI. All adolescents were free of psychotropic and other 
medication during the whole study period. No structural pathologies were found in their brain anatomy according to brain MRI evaluated by a neuroradiologist (N.L.), and the presence of somatic conditions was ruled out based on blood samples. All subjects consumed less than three cups of coffee daily or the equivalent amount of other caffeinated products. Detailed subject characteristics are described in Table 1.

\section{$\underline{\text { Psychiatric evaluation }}$}

The present and lifetime episodes of DSM-IV axis I disorders were assessed with the Schedule for Affective Disorders and Schizophrenia for School-Age Children-Present and Lifetime version (KSADS-PL), a semi-structured diagnostic interview [28]. All interviews were performed by the same clinician (A.S.U.) and confirmed in a diagnostic meeting with a senior clinician (M.M.). As part of the DSM-IV axial diagnostic procedure, the global assessment of functioning scale (GAF; numeric range of 0-100) was used according to DSM-IV guidelines to assess overall psychosocial functioning [1]. GAF has been previously used in studies among adolescents $[29,30]$.

Depression symptom severity was assessed with two different scales: the 21-item Beck Depression Inventory (BDI-21), and the Hamilton Depression Rating Scale (HDRS). The BDI-21 is a standardized 21-item self-rating questionnaire [31], which has been well studied also in adolescents [32, 33]. The subjects were asked to rate each of the symptoms on a 4-point scale ranging from 0 (Not at all) to 3 (Severely) according to the severity of the symptom (sum score range $0-63$ ). The HDRS is a widely used and standardized 17-item depression severity scale, in which each of the depressive symptoms is rated by the clinician on a scale of 0-2 or 0-4 points (total sum score range 0-52) [34]. 
The HDRS has been originally developed for adults, but it has previously been successfully applied to study adolescents (e.g. [4, 35-37]).

To complement the psychiatric evaluation, subjects also filled in the Alcohol Use Disorder Identification Test (AUDIT) [38], and the Beck Anxiety Inventory (BAI) [39].

\section{Assessment of sleep}

Insomnia symptoms were assessed with Athens Insomnia Scale (AIS), a validated self-report questionnaire designed for quantifying sleep difficulties during the past month based on the ICD10 criteria [40]. It consists of eight items rated on a scale of 0-3 (total sum score range 0-24) on sleep induction, awakenings during the night, final awakening, total sleep duration, sleep quality, daytime well-being, daytime functioning capacity, and sleepiness during the day.

Daytime sleepiness symptoms were measured with the Pediatric Daytime Sleepiness Scale (PDSS) [41], a self-rated sleepiness scale specially designed for use among school-aged adolescents. The PDSS consists of 8 items rated on a scale of 0-4 (total sum score range $0-32$ ) related to frequency of falling asleep/drowsiness in class and while doing homework, daytime alertness, daytime tiredness/grumpiness, troubles waking up, falling back to sleep after being awakened, need for outside help to wake up, and thoughts of needing more sleep.

Sleep length and sleep efficiency referred to sleep period were assessed with ambulatory polysomnography performed in the adolescents' home environment for two consecutive nights. The recordings included electroencephalogram (EEG), electro-oculogram (EOG), and chin electromyogram (EMG) recordings and was performed using standard guidelines (Embla, Flaga Hf. 
Medical devices; EEG positions according to the International 10-20 system; derivations F4-M1, C4-M1, O2-M1 and backup derivations F3-M2, C3-M2, and O1-M2; sampling rate $200 \mathrm{~Hz})$. The recordings were scored manually in 30 -s epochs by a certified sleep technologist blinded to the subgroup status of the subjects using standard criteria [42] and total sleep time and sleep efficiency (time asleep relative to sleep period) were calculated from the scorings. The average values of the two nights were used in the analyses.

\section{Magnetic Resonance Spectroscopy}

Proton Magnetic Resonance Spectroscopy $\left({ }^{1} \mathrm{H}\right.$ MRS) was performed at 3.0 T clinical imager (Verio, Siemens, Erlangen, Germany) in the morning after the two nights of polysomnographic recordings, starting between 10:30 and 12 am. Patients lay in a supine position, and a 32 channel head coil was used in data collection. T2 weighted turbo spin echo images (repetition time (TR) of 3630 and echo time (TE) of $96 \mathrm{~ms}$ ) were collected in transaxial, sagittal, and coronal planes in order to enable a careful positioning of MRS voxel and to screen possible anomalies. Automatic preparation and shimming procedure was followed by manual shimming before data acquisition. PRESS localization technique with TR of $10000 / 2000 \mathrm{~ms}$, TE of $30 / 30 \mathrm{~ms}$ and $2 / 96$ acquisitions were used to obtain unsuppressed reference spectra and water suppression spectra, respectively.

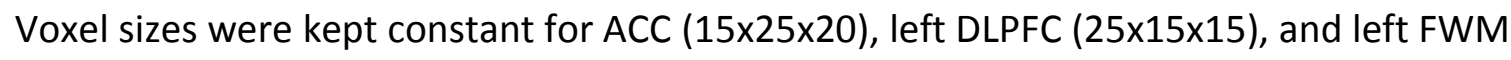
$(15 \times 15 \times 15)$ in each subject.

LCModel v6.3 (http://s-provencher.com/pages/lcmodel.shtml) was used to assess the concentrations of $\mathrm{N}$-acetylaspartate (NAA), total creatine $(\mathrm{tCr})$, choline containing compounds (Cho), total glutamine plus glutamate (Glx), and myo-inositol (ml). Also, signal-to-noise ratio (SNR) 
and full width at half maximum (FWHM) were determined from each spectra. The typical location

of the ${ }^{1} \mathrm{H}$ MRS voxels and representative ${ }^{1} \mathrm{H}$ MR spectra are shown in Fig. 1.

\section{$\underline{\text { Statistical analyses }}$}

Statistical analyses were performed with the IBM SPSS Statistics Version 22 software. Normality of the data was assessed with the Kolmogorov-Smirnov test of normality. Comparisons between subgroups were performed with one-way analysis of variance (ANOVA) or non-parametric independent samples Kruskal-Wallis tests in case of non-normal distribution of the data. To assess correlations between $\mathrm{ml}$ concentrations and clinical measures (TST, sleep efficiency, BDI-21 total score, HDRS, BAI, AIS, PDSS, GAF), correlation analyses using the Pearson's correlation analysis or the Spearman's non-parametric correlation analysis (in case of non-normal distribution of the data) were performed. Findings were considered statistically significant at the $p<0.05$ level.

\section{Results}

\section{Participant characteristics}

Participants were on average $16.0 \pm 0.8$ (mean \pm SD) years old. The subgroups of cases and controls did not differ in terms of their age, body mass index (BMI), serum testosterone levels, alcohol use, or anxiety symptoms (one-way ANOVA n.s.; Table 1).

No axis-I diagnoses were found among the controls, and the cases were confirmed to suffer from depressive disorder (lifetime first depressive episode for 6 , second episode for 2 of the subjects; mean length of current depressive episode $52 \pm 52$ weeks), except for one patient suffering only 
from a circadian rhythm sleep disorder with minor mood symptoms. This non-depressed subject was discarded from the group comparisons, but his data was used in the correlational analyses of the total sample. None of the subjects suffered from bipolar disorder nor manifested psychotic features of depression. Comorbid anxiety disorder was present in one, and comorbid disruptive behavior disorder in one subject, while others did not have comorbid axis-I disorders.

\section{Quality of the ${ }^{1} \mathrm{H}$ MRS spectra}

Mean signal-to-noise ratios (SNR) for ACC, DLPFC, and FWM spectra were $46 \pm 7.38 \pm 6$, and $21 \pm$ 5, respectively. FWHMs for ACC, DLPFC, and FWM spectra were $4.5 \pm 1.2 \mathrm{~Hz}, 5.7 \pm 1.7 \mathrm{~Hz}$, and 6.3 $\pm 2.3 \mathrm{~Hz}$, respectively. There were no differences in ACC, DLPFC, and FWM spectral quality between control and patient groups measured by SNR or FWHM. Cramer-Rao lower bound values for myo-inositol quantification were $7 \%$ or below in each spectra. Because of technical failure or patient movement, MRS spectra could not be obtained in two cases in the DLPFC area, limiting total sample size to $n=17$ in the DLPFC, and in one case in the FWM, limiting total sample size to $\mathrm{n}=16$ in the FWM.

\section{Subgroup comparisons of metabolite concentrations}

The concentration of myo-inositol was lower in cases vs. controls in both frontal cortical areas $($ ACC: $F(1,16)=10.026 ; p=0.006 ;$ DLPFC: $F(1,14)=5.381 ; p=0.036$; One Way ANOVA; Fig. 2). No significant differences were observed in the concentrations of the other metabolites in either of 
these two cortical brain areas or in any metabolite concentrations in FWM (One-way ANOVA or Independent Samples Kruskal-Wallis tests n.s.; Fig. 2).

\section{Metabolites and clinical measures}

In the total sample, myo-inositol levels in the ACC correlated negatively with depression severity (HDRS, BDI-21), level of anxiety (BAI), insomnia symptoms (AIS), daytime sleepiness symptoms (PDSS), and positively with total sleep time (TST; Fig. 3) and overall psychosocial functioning (GAF). Myo-inositol level in the DLPFC correlated negatively with depression severity (HDRS) and positively with total sleep time (TST). Other correlations of $\mathrm{ml}$ with clinical measures remained statistically non-significant. The results are presented in detail in Table 2.

In order to examine whether the significant associations between $\mathrm{ml}$ and sleep measures are confounded by depressive symptoms, we performed additional partial correlation analyses, in which depression severity was controlled for (partial correlation analyses; BDI-21 total score without sleep item as covariate). The correlations between $\mathrm{ml}$ in the ACC and TST (correlation coefficient $r=0.582 ; p=0.011)$, and $\mathrm{ml}$ in the ACC and PDSS $(r=-0.543 ; p=0.024)$ remained significant. The correlations between $\mathrm{ml}$ in the DLPFC and TST $(r=0.492 ; p=0.053)$, and between $\mathrm{ml}$ in the ACC and AIS $(r=-0.358 ; p=0.145)$ did not remain statistically significant.

The correlations of other metabolites with clinical measures are presented in the supplementary material Table 1. In summary, in these analyses $\mathrm{tCr}$ concentrations in the ACC correlated negatively with HDRS $(r=-0.482 ; p=0.037)$ and AIS $(r=-0.514 ; p=0.024 ;$ Pearson's correlation), while tCr concentrations in the DLPFC did not correlate with clinical measures. NAA, Cho, and GIx 
concentrations did not correlate with any of the clinical measures in either frontal cortical area. In FWM, metabolite concentrations did not correlate with any of the clinical measures.

\section{Discussion}

The main finding of this study was that frontal cortex myo-inositol is lower in depressed adolescent boys as compared to healthy controls, and also correlates with sleep length and daytime sleepiness symptoms when severity of depression is controlled for. This implies that both poor sleep and depression may be linked to similar neurometabolic pathways in the frontal cortex. These metabolic alterations appear specific to the cortex since they were not observed in frontal white matter.

Myo-inositol is a naturally occurring glucose isomer which has a number of known roles in the brain. Myo-inositol was initially found in astrocytes, and was therefore proposed as a glia-specific marker [43]. It has, however, also been detected in neuronal cells [44]. It acts as an organic osmolyte involved in maintenance of cell volume, it is required for the synthesis of cell membrane phospholipids, and it acts as a precursor in the phosphatidylinositol (PI) second messenger system $[45,46]$. The PI cycle is activated following ligand binding to a number of cell surface receptors, including those for serotonin, glutamate, histamine, and dopamine, leading to increased second messengers inositol triphosphate (IP3) and diacylglycerol (DAG), which initiate different cascades of cellular events, including mobilization of intracellular calcium and activation of protein kinase $C$ (PKC), which, in turn, have multiple downstream cellular effects $[45,46]$. The source of neuronal $\mathrm{ml}$ is primarily the recycling of PI cycle constituents, but some of the total $\mathrm{ml}$ is synthesized in brain from glucose and some transported from blood [47]. Our findings of lower myo-inositol in 
depressed adolescents with sleep symptoms may point towards an imbalance in the second messenger signaling system.

Considering its widespread neurometabolic role, it is not surprising that altered myo-inositol concentrations have been previously detected in a variety of neurological, psychiatric and behavioural conditions, including e.g. head injuries, Alzheimer's disease, attention deficithyperactivity disorder (ADHD), obsessive-compulsive disorder, sleep disorders, as well as mood disorders in different age groups [48-55]. In particular, reduced cerebral $\mathrm{ml}$ concentration has been suggested as a neurochemical biomarker for depression: lower inositol has been reported in the CSF of depressed patients [56] as well as in postmortem frontal cortex of suicide victims and bipolar disorder patients [57]. Some ${ }^{1} \mathrm{H}$ MRS studies have observed lower cerebral ml concentrations in depressed patients as compared to controls [48,58-60]. On the contrary, bipolar disorder may be characterized by elevated frontal cortex ml concentrations and the anti-manic effects of lithium may be associated with a reduction of $\mathrm{ml}$ [61]. Further, electro-convulsive treatment (ECT) may increase $\mathrm{ml}$ concentrations [60]. These results are not, however, unanimous, as some studies have reported increased or non-different $\mathrm{ml}$ levels in depressed patients as compared to healthy controls $[24,62,63]$. Inositol is widely present in a range of foods (fruits, plants, meats, whole-grain cereals) and available as a dietary supplement. Currently evidence is unclear whether or not inositol is of benefit in the treatment of depression [64].

The results of the current study support earlier findings on decreased cortical myo-inositol in depression, particularly in the adolescent age group, and encourage further studies on the role of $\mathrm{ml}$ in depression and associated sleep symptoms. Understanding these pathophysiological 
phenomena early in the course of depression would be crucial not only in furthering our scientific understanding of the links between poor sleep and mood, but also in developing targeted, effective, and hopefully even preventive interventions [6].

Less is known on the associations between $\mathrm{ml}$ and sleep. In healthy older people, poorer sleep quality and less efficient sleep correlated with higher hippocampal $\mathrm{ml} / \mathrm{tCr}$ ratios, which were hypothesized by the authors to associate with hippocampal glial alterations [50]. The authors also pointed out, however, that their findings may reflect neurodegenerative/pathophysiological processes in this age group, similar to those seen in Alzheimer's disease $[50,52,65,66]$. The contrast between the findings by Cross et al. (pointing towards higher $\mathrm{ml}$ in relation with poor sleep in older people) and our findings (pointing towards lower $\mathrm{ml}$ in relation with poor sleep in adolescents) may thus be at least partly explained by factors related to maturational or neurodegenerational processes. In addition, brain region specific factors may also contribute to the differences: $\mathrm{ml}$ concentration $[46,67]$ and neuronal activity during the sleep-wake cycle $[68]$ differs between the hippocampi vs. frontal cortical areas. The study by Cross et al. concentrated on the hippocampi and did not yield results from the frontal cortex, and our study concentrated on frontal brain areas only. The frontal cortex (more specifically the ACC) was the region of interest in the study by Naismith et al. reporting an association between sleep midpoint and altered glutamatergic processes among young people with affective disorders. However, ml was not among the neurometabolites of interest in their study [27].

To the best of our knowledge, our study is the first to demonstrate an association between subjective and objective sleep measures and frontal cortex myo-inositol concentrations in a 
sample of adolescent boys. Further, while our study reveals that depressed adolescents show lower cortical myo-inositol concentrations as compared to healthy controls, depression does not fully explain the associations of $\mathrm{ml}$ with sleep length and daytime sleepiness. Both sleep length and depression may thus affect the same neurometabolic pathways in the maturing frontal cortex of adolescents in an additive manner.

In addition to findings related to $\mathrm{ml}$, we found that $\mathrm{tCr}$ concentrations in the ACC correlated negatively with depression severity and insomnia symptoms. $\mathrm{tCr}$ has conventionally been used as a reference metabolite, and very few studies with inconsistent findings have assessed $\mathrm{tCr}$ concentrations in psychiatric disorders [69]. However, $\mathrm{tCr}$ is not a constant compound in the brain, but plays a pivotal role in cell energy homeostasis, and thus lower $\mathrm{tCr}$ levels related to insomnia and depressive symptoms may indicate impaired energy metabolism [46]. The fact that no significant findings were detected in other MRS metabolites may be attributed to the small sample size, which may not allow us to detect subtle differences.

Important strengths of this study include the homogeneous nature of the sample in terms of gender and age, the lack of psychotropic and other medication use among the subjects, the use of polysomnography (the gold standard of sleep research) to determine sleep length, the detailed psychiatric evaluation of the participants, and the inclusion of a control group. Further, the patient and control groups were well matched for their age and hormonal status. Since antidepressive medication may at least region-specifically affect the brain MRS metabolic profile [70], we find the lack of psychotropic medication use a particular strength of our study. 
Limitations of the study include most importantly the small sample size, which allows us to make only preliminary conclusions on the results. Further studies with larger sample sizes are needed especially to conduct more specific multi-variable analyses in subgroups. Further, as our study was cross-sectional, we cannot make definite inferences on causality: are shorter sleep and depressive symptoms actually causing a change in myo-inositol metabolism, or are the alterations in myoinositol underlying the clinical phenotypes? This remains to be answered in longitudinal study designs. Excluding female participants from the sample on one hand limits the generalizability of the findings to adolescent girls, but on the other also excluded the potential effects of the menstrual cycle phase on sleep and brain metabolism [71, 72]. Boys and girls also differ from each other in terms of brain maturational changes during adolescence [73]. In addition, a limitation of this study is the lack of correction for partial volume effects. In theory, gray matter atrophy could lead to an increased CSF fraction inside the VOI and therefore decreased metabolite levels. Should this occur, a decrease in all metabolite levels and SNR would be expected, but we did not see differences between groups in any other metabolite nor SNR than $\mathrm{ml}$.

\section{Conclusion}

Lower frontal cortex $\mathrm{ml}$ may point towards a disturbed second messenger system and be linked to the pathophysiology of depression and concomitant sleep symptoms among maturing adolescents. Short sleep and daytime sleepiness may be associated with frontal cortical ml independently from depression. Further studies are needed to explore the role of $\mathrm{ml}$ in depression and associated sleep symptoms in more detail. 


\section{Acknowledgements}

The study has been financially supported by the Academy of Finland (grant number 276612 to A.S.U.), the Emil Aaltonen Foundation, the Finnish Medical Foundation, the Finnish Brain Foundation, the Orion Farmos Research Foundation, the Päivikki and Sakari Sohlberg Foundation, the Foundation for Psychiatric Research, and a special federal grant (TYH 2013342 to T.P.).

\section{Conflicts of interest}

No conflicts of interest.

\section{References}

1. American Psychiatric Association: Diagnostic and Statistical Manual of Mental Disorders DSM IV. Washington, DC: American Psychiatric Association; 1994.

2. Barbe RP, Williamson DE, Bridge JA, Birmaher B, Dahl RE, Axelson DA, et al.: Clinical differences between suicidal and nonsuicidal depressed children and adolescents. J Clin Psychiatry 2005;66:492-8.

3. Liu X, Buysse DJ, Gentzler AL, Kiss E, Mayer L, Kapornai K, et al.: Insomnia and hypersomnia associated with depressive phenomenology and comorbidity in childhood depression. Sleep 2007;30:83-90.

4. Urrila AS, Karlsson L, Kiviruusu O, Pelkonen M, Strandholm T, Marttunen M: Sleep complaints among adolescent outpatients with major depressive disorder. Sleep Med 2012;13:816-23.

5. Manglick M, Rajaratnam SM, Taffe J, Tonge B, Melvin G: Persistent sleep disturbance is associated with treatment response in adolescents with depression. Australian \& New Zealand J Psychiatry 2013;47:556-63.

6. Urrila AS, Paunio T, Palomaki E, Marttunen M: Sleep in adolescent depression: physiological perspectives. Acta Physiol (Oxf) 2015;213:758-77. 
7. Kurth S, Ringli M, Geiger A, LeBourgeois M, Jenni OG, Huber R: Mapping of cortical activity in the first two decades of life: a high-density sleep electroencephalogram study. J Neurosci 2010;30:13211-9.

8. Buchmann A, Ringli M, Kurth S, Schaerer M, Geiger A, Jenni OG, et al.: EEG sleep slow-wave activity as a mirror of cortical maturation. Cerebral Cortex 2011;21:607-15.

9. Gogtay N, Giedd JN, Lusk L, Hayashi KM, Greenstein D, Vaituzis AC, et al.: Dynamic mapping of human cortical development during childhood through early adulthood. Proc Natl Acad Sci U S A 2004;101:8174-9.

10. Bourisly AK, El-Beltagi A, Cherian J, Gejo G, Al-Jazzaf A, Ismail M: A voxel-based morphometric magnetic resonance imaging study of the brain detects age-related gray matter volume changes in healthy subjects of 21-45 years old. Neuroradiol J 2015;28:450-9.

11. Paus T, Keshavan M, Giedd JN: Why do many psychiatric disorders emerge during adolescence? Nature Rev Neurosci 2008;9:947-57.

12. Pizzagalli DA: Frontocingulate dysfunction in depression: toward biomarkers of treatment response. Neuropsychopharmacology 2011;36:183-206.

13. Hulvershorn LA, Cullen K, Anand A: Toward dysfunctional connectivity: a review of neuroimaging findings in pediatric major depressive disorder. Brain Imaging Behav 2011;5:307-28.

14. Weber M, Webb CA, Deldonno SR, Kipman M, Schwab ZJ, Weiner MR, et al.: Habitual 'sleep credit' is associated with greater grey matter volume of the medial prefrontal cortex, higher emotional intelligence and better mental health. J Sleep Res 2013;22:527-34.

15. Killgore WD, Schwab ZJ, Kipman M, DelDonno SR, Weber M: Voxel-based morphometric gray matter correlates of daytime sleepiness. Neurosci Lett 2012;518:10-3.

16. Urrila AS, Artiges E, Massicotte J, Miranda R, Vulser H, Bézivin-Frere $P$, Lapidaire W, Lemaître H, Penttilä J, Conrod PJ, Garavan H, Paillère Martinot M-L, Martinot J-L, the IMAGEN consortium: Sleep habits, academic performance, and the adolescent brain structure. Sci Reports $2017 ; 7,41678$.

17. Drummond SP, Brown GG, Stricker JL, Buxton RB, Wong EC, Gillin JC: Sleep deprivation-induced reduction in cortical functional response to serial subtraction. Neuroreport 199916;10:3745-8.

18. Horne JA: Human sleep, sleep loss and behaviour. Implications for the prefrontal cortex and psychiatric disorder. Br J Psychiatry 1993;162:413-9.

19. Joo EY, Tae WS, Lee MJ, Kang JW, Park HS, Lee JY, et al.: Reduced brain gray matter concentration in patients with obstructive sleep apnea syndrome. Sleep 2010;33:235-41.

20. Altena E, Van Der Werf YD, Sanz-Arigita EJ, Voorn TA, Rombouts SA, Kuijer JP, et al.: Prefrontal hypoactivation and recovery in insomnia. Sleep 2008;31:1271-6. 
21. Altena E, Vrenken H, Van Der Werf YD, van den Heuvel OA, Van Someren EJ: Reduced orbitofrontal and parietal gray matter in chronic insomnia: a voxel-based morphometric study. Biol Psychiatry 2010;67:182-5.

22. Steingard RJ, Yurgelun-Todd DA, Hennen J, Moore JC, Moore CM, Vakili K, et al.: Increased orbitofrontal cortex levels of choline in depressed adolescents as detected by in vivo proton magnetic resonance spectroscopy. Biol Psychiatry 2000;48:1053-61.

23. Farchione TR, Moore GJ, Rosenberg DR: Proton magnetic resonance spectroscopic imaging in pediatric major depression. Biol Psychiatry 2002;52:86-92.

24. Caetano SC, Fonseca M, Olvera RL, Nicoletti M, Hatch JP, Stanley JA, et al.: Proton spectroscopy study of the left dorsolateral prefrontal cortex in pediatric depressed patients. Neurosci Lett 2005;384:321-6.

25. Mirza Y, Tang J, Russell A, Banerjee SP, Bhandari R, Ivey J, et al.: Reduced anterior cingulate cortex glutamatergic concentrations in childhood major depression. J Am Acad Child Adolesc Psychiatry 2004;43:341-8.

26. Rosenberg DR, Macmaster FP, Mirza Y, Smith JM, Easter PC, Banerjee SP, et al.: Reduced anterior cingulate glutamate in pediatric major depression: a magnetic resonance spectroscopy study. Biol Psychiatry 2005;58:700-4.

27. Naismith SL, Lagopoulos J, Hermens DF, White D, Duffy SL, Robillard R, et al.: Delayed circadian phase is linked to glutamatergic functions in young people with affective disorders: a proton magnetic resonance spectroscopy study. BMC Psychiatry 2014;14:345.

28. Kaufman J, Birmaher B, Brent D, Rao U, Flynn C, Moreci P, et al.: Schedule for Affective Disorders and Schizophrenia for School-Age Children-Present and Lifetime Version (K-SADS-PL): initial reliability and validity data. J Am Acad Child Adolesc Psychiatry 1997;36:980-8.

29. Wentz E, Gillberg IC, Anckarsater H, Gillberg C, Rastam M: Adolescent-onset anorexia nervosa: 18-year outcome. Br J Psychiatry 2009;194:168-74.

30. Ulberg R, Hersoug AG, Hoglend P: Treatment of adolescents with depression: the effect of transference interventions in a randomized controlled study of dynamic psychotherapy. Trials 2012;13:159.

31. Beck AT, Ward CH, Mendelson M, Mock J, Erbaugh J: An inventory for measuring depression. Arch Gen Psychiatry 1961;4:561-71.

32. Marton $\mathrm{P}$, Churchard $\mathrm{M}$, Kutcher S, Korenblum M: Diagnostic utility of the Beck Depression Inventory with adolescent psychiatric outpatients and inpatients. Can J Psychiatry1991;36:428-31.

33. Brooks SJ, Kutcher S: Diagnosis and measurement of adolescent depression: a review of commonly utilized instruments. J Child Adoles Psychopharmacology 2001;11:341-76. 
34. Hamilton M: A rating scale for depression. J Neurol Neurosurg Psychiatry. 1960;23:56-62.

35. Emslie GJ, Findling RL, Yeung PP, Kunz NR, Li Y: Venlafaxine ER for the Treatment of Pediatric Subjects With Depression: Results of Two Placebo-Controlled Trials. J Am Acad Child Adolesc Psychiatry 2007;46:479-88.

36. Mufson L, Dorta KP, Wickramaratne $P$, Nomura $Y$, Olfson $M$, Weissman MM: A Randomized Effectiveness Trial of Interpersonal Psychotherapy for Depressed Adolescents. Arch Gen Psychiatry 2004;61:577-84.

37. Clarke G, Debar L, Lynch F, Powell J, Gale J, O'Connor E, et al.: A randomized effectiveness trial of brief cognitive-behavioral therapy for depressed adolescents receiving antidepressant medication. J Am Acad Child Adolesc Psychiatry 2005;44:888-98.

38. Saunders JB, Aasland OG, Babor TF, de la Fuente JR, Grant M: Development of the Alcohol Use Disorders Identification Test (AUDIT): WHO Collaborative Project on Early Detection of Persons with Harmful Alcohol Consumption--II. Addiction 1993;88:791-804.

39. Beck AT, Epstein N, Brown G, Steer RA: An inventory for measuring clinical anxiety: psychometric properties. J Consult Clin Psychology 1988;56:893-7.

40. Soldatos CR, Dikeos DG, Paparrigopoulos TJ: Athens Insomnia Scale: validation of an instrument based on ICD-10 criteria. J Psychosom Res 2000;48:555-60.

41. Drake C, Nickel C, Burduvali E, Roth T, Jefferson C, Pietro B: The pediatric daytime sleepiness scale (PDSS): sleep habits and school outcomes in middle-school children. Sleep 2003;26:455-8.

42. Iber C, Ancoli-Israel S, Chesson AL, Quan SF: The AASM Manual for the Scoring of Sleep and Associated Events: Rules, Terminology and Technical Specifications. Westchester, Ill: American Academy of Sleep Medicine; 2007.

43. Brand A, Richter-Landsberg C, Leibfritz D: Multinuclear NMR studies on the energy metabolism of glial and neuronal cells. Dev Neurosci 1993;15:289-98.

44. Novak JE, Turner RS, Agranoff BW, Fisher SK: Differentiated human NT2-N neurons possess a high intracellular content of myo-inositol. J Neurochem 1999;72:1431-40.

45. Kim H, McGrath BM, Silverstone PH: A review of the possible relevance of inositol and the phosphatidylinositol second messenger system (PI-cycle) to psychiatric disorders--focus on magnetic resonance spectroscopy (MRS) studies. Human Psychopharmacol 2005;20:309-26.

46. Rae CD: A Guide to the Metabolic Pathways and Function of Metabolites Observed in Human Brain 1 H Magnetic Resonance Spectra. Neurochem Res 2014;39:1-36.

47. Spector R: Myo-inositol transport through the blood-brain barrier. Neurochem Res 1988;13:785-7. 
48. Gruber S, Frey R, Mlynarik V, Stadlbauer A, Heiden A, Kasper S, et al.: Quantification of metabolic differences in the frontal brain of depressive patients and controls obtained by $1 \mathrm{H}-\mathrm{MRS}$ at 3 Tesla. Invest Radiol 2003;38:403-8.

49. Cross NE, Lagopoulos J, Duffy SL, Cockayne NL, Hickie IB, Lewis SJG, et al.: Sleep quality in healthy older people: relationship with $1 \mathrm{H}$ magnetic resonance spectroscopy markers of glial and neuronal integrity. Behav Neurosci 2013;127:803-10.

50. Poryazova R, Schnepf B, Werth E, Khatami R, Dydak U, Meier D, et al.: Evidence for metabolic hypothalamo-amygdala dysfunction in narcolepsy. Sleep 2009;32:607-13.

51. Voevodskaya O, Sundgren PC, Strandberg O, Zetterberg H, Minthon L, Blennow K, et al.: Myoinositol changes precede amyloid pathology and relate to APOE genotype in Alzheimer disease. Neurology 2016;86:1754-61.

52. Sarchielli P, Presciutti O, Alberti A, Tarducci R, Gobbi G, Galletti F, et al.: A 1 H magnetic resonance spectroscopy study in patients with obstructive sleep apnea. Eur J Neurol 2008;15:1058-64.

53. Garnett MR, Blamire AM, Corkill RG, Cadoux-Hudson TA, Rajagopalan B, Styles P: Early proton magnetic resonance spectroscopy in normal-appearing brain correlates with outcome in patients following traumatic brain injury. Brain 2000;123:2046-54.

54. Tafazoli S, O'Neill J, Bejjani A, Ly R, Salamon N, McCracken JT, et al.: $1 \mathrm{H}$ MRSI of middle frontal gyrus in pediatric ADHD. J Psychiatr Res 2013;47:505-12.

55. Ortiz AE, Ortiz AG, Falcon C, Morer A, Plana MT, Bargallo N, et al.: 1H-MRS of the anterior cingulate cortex in childhood and adolescent obsessive-compulsive disorder: a case-control study. Eur Neuropsychopharmacology 2015;25:60-8.

56. Barkai Al, Dunner DL, Gross HA, Mayo P, Fieve RR: Reduced myo-inositol levels in cerebrospinal fluid from patients with affective disorder. Biol Psychiatry 1978;13:65-72.

57. Shimon H, Agam G, Belmaker RH, Hyde TM, Kleinman JE: Reduced frontal cortex inositol levels in postmortem brain of suicide victims and patients with bipolar disorder. Am J Psychiatry 1997;154:1148-50.

58. Coupland NJ, Ogilvie CJ, Hegadoren KM, Seres P, Hanstock CC, Allen PS: Decreased prefrontal Myo-inositol in major depressive disorder. Biol Psychiatry 2005;57:1526-34.

59. Jarnum H, Eskildsen SF, Steffensen EG, Lundbye-Christensen S, Simonsen CW, Thomsen IS, et al.: Longitudinal MRI study of cortical thickness, perfusion, and metabolite levels in major depressive disorder. Acta Psychiatr Scand 2011;124:435-46.

60. Chen L, Dai H, Dai Z, Xu C, Wu R: Anterior cingulate cortex and cerebellar hemisphere neurometabolite changes in depression treatment: A $1 \mathrm{H}$ magnetic resonance spectroscopy study. Psychiatry Clin Neurosci 2014;68:357-64. 
61. Davanzo P, Thomas MA, Yue K, Oshiro T, Belin T, Strober M, et al.: Decreased anterior cingulate myo-inositol/creatine spectroscopy resonance with lithium treatment in children with bipolar disorder. Neuropsychopharmacology 2001;24:359-69.

62. Auer DP, Putz B, Kraft E, Lipinski B, Schill J, Holsboer F: Reduced glutamate in the anterior cingulate cortex in depression: an in vivo proton magnetic resonance spectroscopy study. Biol Psychiatry 2000;47:305-13.

63. Taylor MJ, Selvaraj S, Norbury R, Jezzard P, Cowen PJ: Normal glutamate but elevated myoinositol in anterior cingulate cortex in recovered depressed patients. J Affect Disord 2009;119:1869.

64. Taylor MJ, Wilder H, Bhagwagar Z, Geddes J: Inositol for depressive disorders. Cochrane Database of Systematic Reviews. 2004;9:2.

65. Gao F, Barker PB: Various MRS application tools for Alzheimer disease and mild cognitive impairment. Ajnr: American Journal of Neuroradiology 2014;35:S4-11.

66. Miller BL, Moats RA, Shonk T, Ernst T, Woolley S, Ross BD: Alzheimer disease: depiction of increased cerebral myo-inositol with proton MR spectroscopy. Radiology 1993;187:433-7.

67. Fisher SK, Novak JE, Agranoff BW: Inositol and higher inositol phosphates in neural tissues: homeostasis, metabolism and functional significance. J Neurochem 2002;82:736-54.

68. Maquet P: Brain mechanisms of sleep: contribution of neuroimaging techniques. J Psychopharmacology 1999;13:S25-8.

69. Yang XR, Langevin LM, Jaworska N, Kirton A, Lebel RM, Harris AD, et al.: Proton spectroscopy study of the dorsolateral prefrontal cortex in youth with familial depression. Psychiatry Clin Neurosci 2016;70:269-77.

70. Taylor M, Murphy SE, Selveraj S, Wylezinska M, Jezzard P, Cowen PJ, Evans J: Differential effects of citalopram and reboxetine on cortical Glx measured with proton MR spectroscopy. J Psychopharmacology 2008;22:473-6.

71. Dzaja A, Arber S, Hislop J, Kerkhofs M, Kopp C, Pollmacher T, et al.: Women's sleep in health and disease. J Psychiatr Res 2005;39:55-76.

72. Rasgon NL, Thomas MA, Guze BH, Fairbanks LA, Yue K, Curran JG, et al.: Menstrual cyclerelated brain metabolite changes using $1 \mathrm{H}$ magnetic resonance spectroscopy in premenopausal women: a pilot study. Psychiatry Res 2001;106:47-57.

73. Lenroot RK, Gogtay N, Greenstein DK, Wells EM, Wallace GL, Clasen LS, et al.: Sexual dimorphism of brain developmental trajectories during childhood and adolescence. Neuroimage 2007;36:1065-73. 
Table and figure legends.

Table 1.

\begin{tabular}{|c|c|c|c|c|}
\hline Variable & & Mean & SD & Range \\
\hline \multirow[t]{3}{*}{ Age $(n=19)$} & & 16.0 & 0.8 & $14.7-17.3$ \\
\hline & Cases $(n=9)$ & 15.8 & 0.9 & $14.7-17.3$ \\
\hline & Controls $(n=10)$ & 16.2 & 0.7 & $14.8-17.2$ \\
\hline \multirow[t]{3}{*}{ BMI $(n=19)$} & & 20.9 & 2.8 & $16.8-27.6$ \\
\hline & Cases $(n=9)$ & 21.4 & 3.7 & $16.8-27.6$ \\
\hline & Controls $(n=10)$ & 20.6 & 1.7 & $17.8-23.8$ \\
\hline \multirow[t]{3}{*}{ S-Testo $(n=18)$} & & 19.9 & 3.7 & $15.0-27.6$ \\
\hline & Cases $(n=9)$ & 20.4 & 3.9 & $15.0-26.3$ \\
\hline & Controls ( $n=9)$ & 19.4 & 3.6 & $15.3-27.6$ \\
\hline \multirow[t]{3}{*}{ BDI-21 (n=19) } & & 9.0 & 10.7 & $0-33$ \\
\hline & Cases $(n=9)$ & $15.8^{*}$ & 11.7 & $1-33$ \\
\hline & Controls $(n=10)$ & $2.8^{*}$ & 4.0 & $0-12$ \\
\hline \multirow[t]{3}{*}{ HDRS (n=19) } & & 5.8 & 6.9 & $0-19$ \\
\hline & Cases $(n=9)$ & $11.9 * *$ & 5.1 & $4-19$ \\
\hline & Controls $(n=10)$ & $0.3 * *$ & 0.7 & $0-2$ \\
\hline \multirow[t]{3}{*}{ BAI $(n=18)$} & & 5.3 & 5.2 & $0-18$ \\
\hline & Cases $(n=8)$ & 7.9 & 5.6 & $1-18$ \\
\hline & Controls $(n=10)$ & 3.2 & 4.1 & $0-13$ \\
\hline
\end{tabular}




$\begin{array}{llll}\text { Cases }(n=9) & 51.6 * * & 6.4 & 43-59 \\ \text { Controls }(n=10) & 81.0^{* *} & 4.6 & 75-90\end{array}$

AIS $(n=19)$

TST (n=19)

456.6

66.0

303.0-563.0

Cases $(n=9)$

431.8

85.0

303.0-563.0

Controls $(n=10)$

479.0

33.6

412.3-528.5

Sleep efficiency $(n=19)$

95.7

6.4

70.7-99.3

Cases $(n=9)$

94.4

9.0

70.7-98.5

Controls ( $n=10)$

96.9

2.8

92.1-99.3

Sample characteristics presented separately for the total sample $(n=19)$, and the cases $(n=9)$ and controls $(n=10) . *$ denotes statistically significant differences between the cases and the controls at a statistical threshold of $p<0.05 ;{ }^{* *}$ denotes statistically significant differences at a statistical threshold of $p<0.001$ (one-way ANOVA). BMI = Body Mass Index; S-Testo = serum testosterone level (nmol/l); BDI-21 = 21-item Beck Depression Inventory; HDRS = Hamilton Depression Rating 
Scale; $\mathrm{BAI}=$ Beck Anxiety Inventory; GAF = Global Assessment of Functioning Scale; AIS = Athens Insomnia Scale; PDSS = Pediatric Daytime Sleepiness Scale, TST = total sleep time (min). 
Table 2.

\begin{tabular}{|c|c|c|c|c|c|c|c|c|c|}
\hline & & BDI-21 & HDRS & BAI & GAF & AIS & PDSS & TST & $\begin{array}{c}\text { Sleep } \\
\text { efficiency }\end{array}$ \\
\hline \multirow[t]{3}{*}{$\mathrm{ml}$ (ACC) } & $r$ &,$- 573^{*}$ &,$- 622^{* *}$ &,$- 552^{\star}$ & , $690^{* *}$ &,$- 658^{* *}$ &,$- 576^{* \star a}$ &, $599^{* *}$ & 103 \\
\hline & $p$ &, 010 & ,004 & ,018 & 001 & ,002 & ,015 & ,007 & ,676 \\
\hline & $\mathbf{n}$ & 19 & 19 & 18 & 19 & 19 & 18 & 19 & 19 \\
\hline \multirow[t]{3}{*}{ ml (DLPFC) } & $r$ & $-0,561^{*}$ &,$- 539^{*}$ &,- 261 & 450 &,- 262 &,$- 395^{a}$ &, $542^{*}$ & 332 \\
\hline & $p$ & ,012 & ,026 & ,329 & ,070 & 309 & 130 & ,025 & 193 \\
\hline & $\mathbf{n}$ & 17 & 17 & 16 & 17 & 17 & 16 & 17 & 17 \\
\hline
\end{tabular}

Correlations between myo-inositol $(\mathrm{ml})$ cortical concentrations and clinical measures. ${ }^{*}$ denotes correlations significant at the $p<0.05$ level, ${ }^{* *}$ denotes correlations significant at the $p<0.01$ level. ${ }^{a}$ denotes Pearson's correlations, all other correlations are Spearman's non-parametric correlations. $\mathrm{ml}=$ myo-inositol; $\mathrm{ACC}=$ anterior cingulate cortex DLPFC $=$ dorsolateral prefrontal cortex. $\mathrm{BDI}-21$ = 21-item Beck Depression Inventory; HDRS = Hamilton Depression Rating Scale; BAI = Beck Anxiety Inventory; GAF = Global Assessment of Functioning Scale; AIS = Athens Insomnia Scale; PDSS = Pediatric Daytime Sleepiness Scale, TST = total sleep time $(\mathrm{min})$. 
Figure 1.

a.

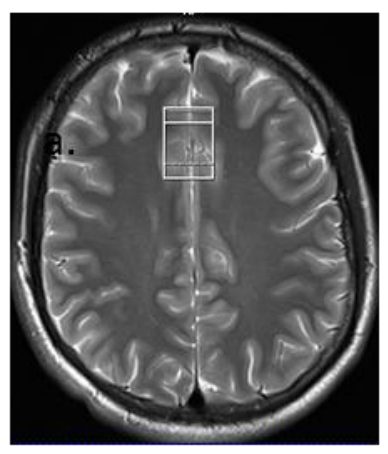

b.

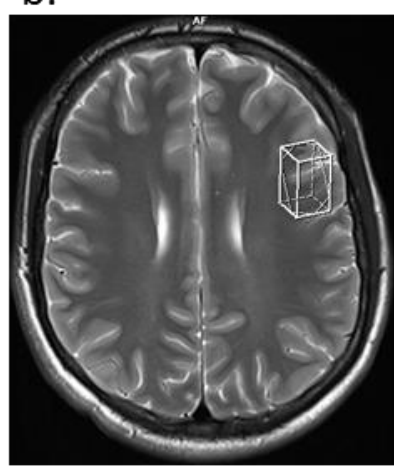

c.

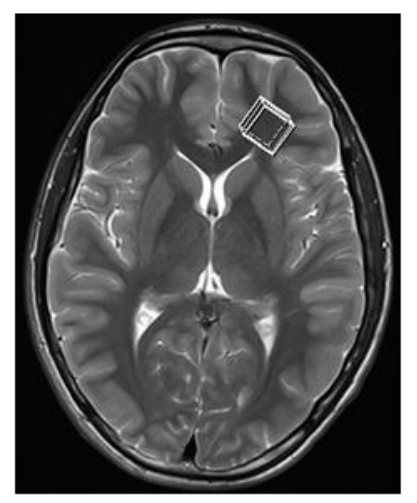

d.

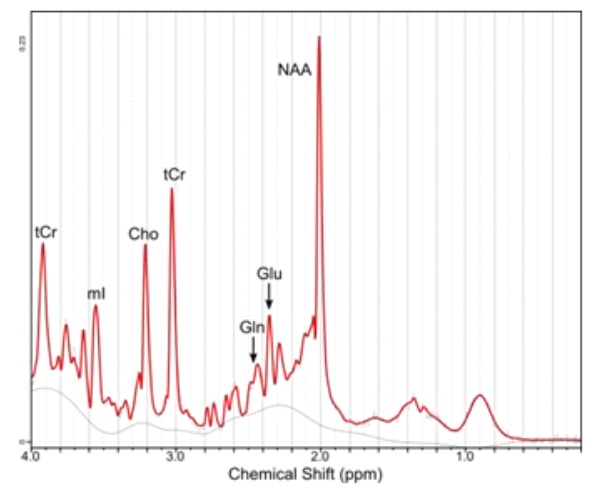

e.

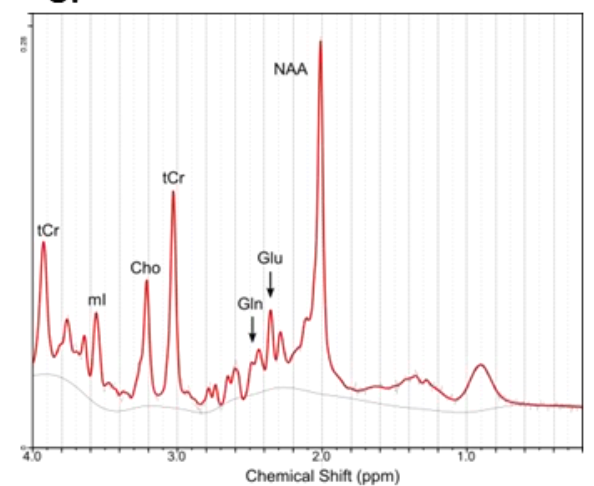

f.

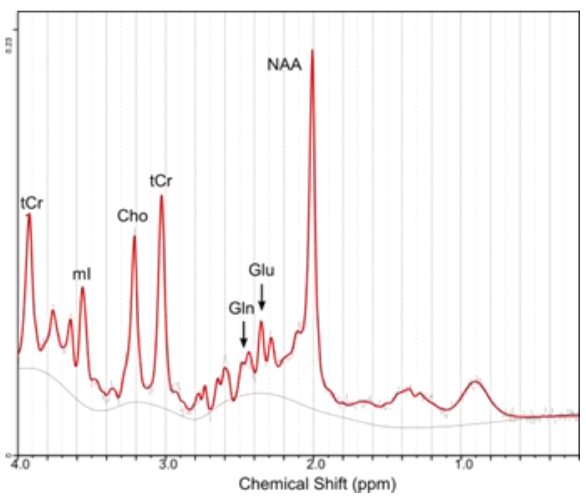

Location of the ${ }^{1} \mathrm{H}$ MRS single voxels in a) the anterior cingulate cortex (ACC), b) in the left dorsolateral prefrontal cortex (DLPFC), and c) frontal white matter (FWM), and the corresponding spectra from d) ACC, e) DLPFC , and f) FWM. tCr = total creatine; $\mathrm{ml}=$ myo-inositol; Cho = choline containing compounds; Gln = glutamine; Glu = glutamate; NAA = N-acetyl aspartate. 
Figure 2.
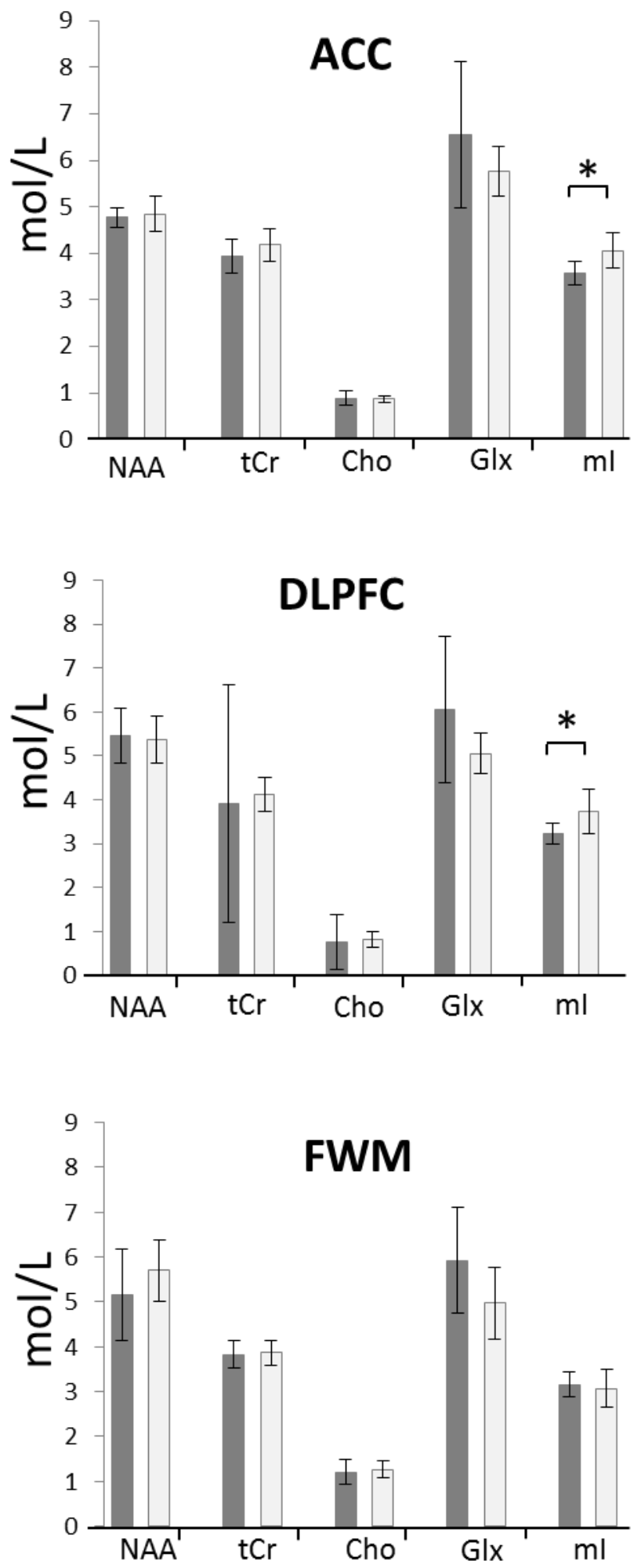
Metabolite concentrations in a) the anterior cingulate cortex (ACC), b) the dorsolateral prefrontal cortex (DLPFC), and c) frontal white matter (FWM). Results are presented separately for the subgroups of depressed patients ( $\ldots$; $n=8$ for ACC, $n=6$ for DLPFC, and $n=7$ for FWM) and controls $(\square ; \mathrm{n}=10$ for all brain areas). Errors bars indicate $\pm \mathrm{SD}$. NAA=N-Acetyl aspartate; $\mathrm{tCr}=$ total creatine; Cho = choline-containing compounds; $\mathrm{Glx}=$ total glutamate-glutamine; $\mathrm{ml}=$ myoinositol. *denotes statistically significant differences between the patients and the controls at a statistical threshold of $p<0.05$; One-Way ANOVA. 
Figure 3.

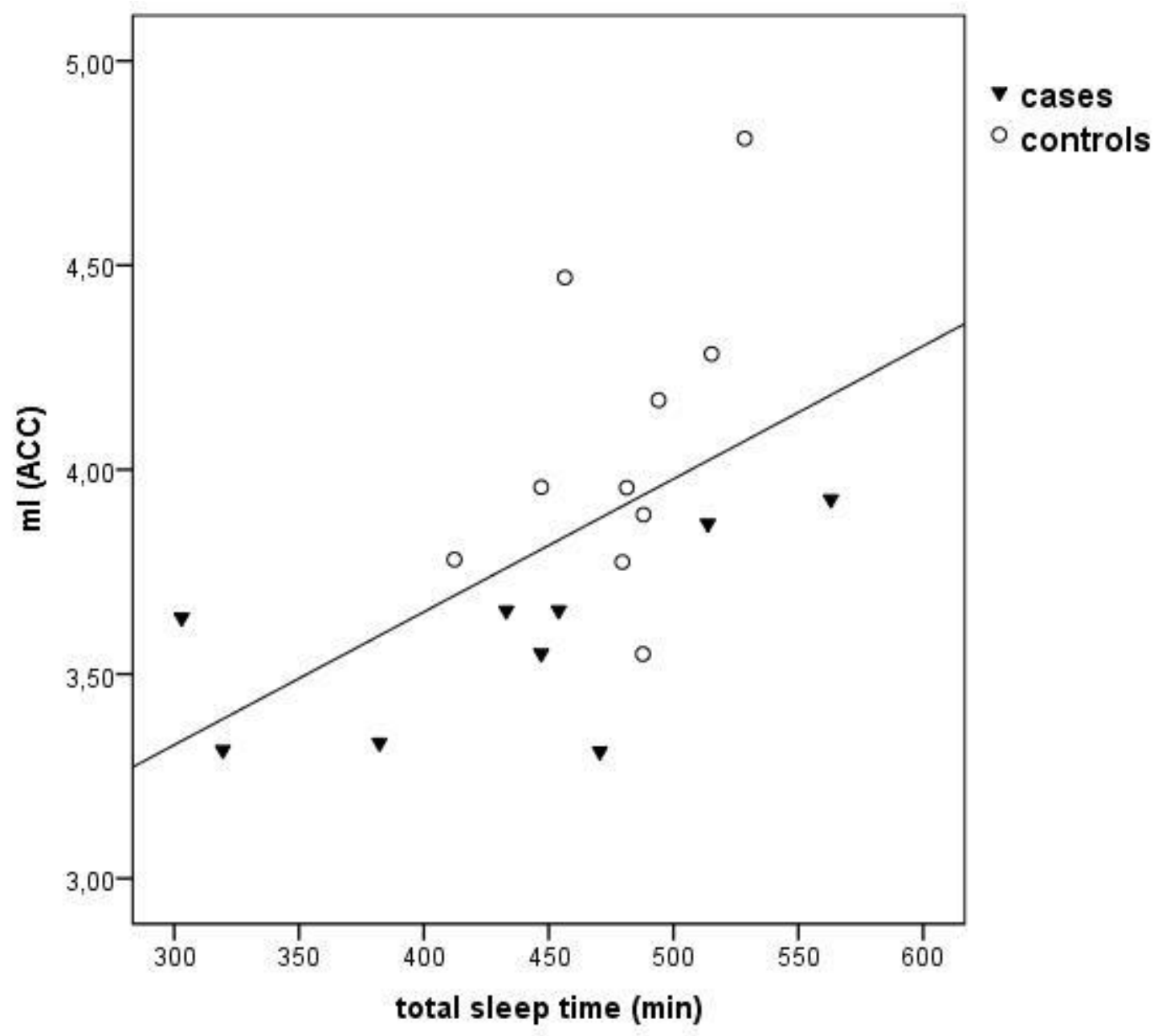

Correlation between total sleep time and myo-inositol $(\mathrm{ml})$ concentrations in the anterior cingulate cortex $(A C C)$ in the total sample $(n=19$; cases $\nabla$ and controls $O$ ). The solid line represents a linear regression line fitted to the data, $R^{2} 0.30$. 